\title{
TECNOLOGÍA PARA LA PRODUCCIÓN ARTESANAL DEL JABÓN PRIETO DE JATROPHA CURCAS L
}

Enrique Casanovas Cosío ${ }^{1}$

Hilder Enrique Vera Saldarriaga ${ }^{2}$

Cesar Roberto Mosquera Cuaces $^{2}$

\section{Resumen}

La producción de jabón artesanal es una práctica local en muchos lugares del mundo, que en Ecuador es una actividad que se realiza el Cantón de Chone de la provincia de Manabí, pero que no está descrito el proceso en literatura científica; y se produce por orientaciones de padres a hijos. En esta investigación se ha tratado de describir la tecnología artesanal de producción del Jabón Prieto con las nueces del piñón (Jatropha curcas L.), para lo cual se empleó un diseño observacional apoyado con encuestas a tres productores. Además, se realizó una comparación entre tres producciones de jabones obtenidos del aceite de la Jatropha con hidróxido de sodio en laboratorios del INIAP y muestras artesanales de los tres productores. Se diagnosticó las características organolépticas, físico-químicas y bacteriológicas en laboratorio autorizado. Los procesos de producción de jabones artesanales son similares y se describe la tecnología en la cual no se encontraron gastos de insumos externos que apunta a la sostenibilidad de su producción. El jabón artesanal es más oscuro y con un olor penetrante parecido al del fruto seco, ambos son de consistencia sólida; que en el jabón artesanal se expresa por la adición de grasa de vaca con ácidos grasos saturados. Los jabones obtenidos presentaron similares valores de pH (alcalinos). El jabón artesanal presentó mayor contenido de humedad (12.73 \%) y menor contenido de grasa (34.77 \%). La variabilidad de los indicadores físico químicos fueron mayores en el jabón artesanal pero siempre con un CV menor de $10.0 \%$, que indica similitud en los procesos en los productores. Desde el punto de vista bacteriológico ambos jabones se declaran aptos para el consumo con recuentos de aerobios mesófilos totales menores que 10 UFC, y ausencia de Echerichia coli, Salmonella sp. y Shigelia sp.

Palabras clave: Bacteriología. Producción artesanal. Calidad. Jabón. Sostenibilidad.

\section{Introducción}

Está definido el impacto negativo que ha producido la acción antrópica desmesurada sobre la naturaleza, que se expresa de forma general en el denominado Cambio climático. Según la Convención Marco de las Naciones Unidas sobre el Cambio Climático, este término solo se usa para referirse al cambio por causas humanas (IPCC, 2001).

Cada día se buscan nuevas alternativas para mitigar los efectos negativos de la industrialización y la alta dependencia de energía fósil, que predomina en los países desarrollados y se ha convertido en un modelo para los países en vías de desarrollo.

La Jatropha curcas L. se ha establecido como especie promisoria para la obtención de biocombustibles, en específico biodiesel, por el contenido de aceite en sus nueces. Entre las ventajas que posee esta planta, originaria de América Central, está su adaptabilidad a tierras áridas, no exigente a riegos y notable producción de aceite por unidad de área con 1590 L, que además tiene un balance de energía positivo (Bruinsma, 2009) (BioDieselSpain, 2006)

Además de esta planta se obtienen otros productos potencialmente útiles como colorantes y taninos, como planta melífera y para la producción de jabón (GUBITS et al., 1999) (CORDERO et al., 2003). Existen reportes

${ }^{1}$ Universidad de Cienfuegos. Cuatro Caminos. Carretera a Rodas, Km $3{ }^{1 / 2}$ Cienfuegos. Profesor invitado UMET- Universidad Metropolitana de Ecuador. Ave. La Coruña. N 26-95 y San Ignacio. Quito (ecasanovas@ucf.edu.cu; ecasanovas@umet.edu.ec )

${ }^{2}$ Estudiantes de Ingeniería en Agronegocios de la UMET- Universidad Metropolitana de Ecuador. 
del aceite extraido de las nueces para la obtención de jabón, que impulsan el desarrollo local en Cabo Verde (ESTEVES, 1960), Zimbawe (KARAVINA et al., 2011) y parcialmente en la India (GMÜNDER et al., 2012).

Actualmente la producción de los jabones es un proceso industrial, que es monopolizado por grandes compañías. Datos recientes (EUROSTAT, 2012) señalan en Europa a la industria del jabón, perfumería y productos de limpieza dentro del rubro de las industrias químicas, como la segunda sección en importancia, solo superada por la producción de fertilizantes, con valores de 14500 millones de euros anuales.

Los métodos de producción artesanal se basan también en la saponificación de los aceites de las nueces sin corteza de la Jatropha, con el álcali presente en la ceniza de maderas y su cocción para la zona de Manabí, provincia de Ecuador. Este proceso aún no está descrito y fundamentado, y se ha trasladado de tal forma de generación en generación.

Se tiene conocimiento de pruebas que se han hecho en el INIAP - Instituto Nacional Autónomo de Investigaciones Agropecuarias (Andrés Viteri), en la producción del Jabón Prieto con el aceite de la Jatropha obtenido por extracción industrial.

La calidad del Jabón Prieto, no está evaluada, ni descrita su tecnología de forma artesanal, cuyos resultados preliminares se pretende en esta investigación presentar y comparar los parámetros principales con jabones obtenidos con aceite industrial.

\section{Materiales y Métodos}

La presente investigación se realizó en el Cantón de Chone de la provincia de Manabí, Ecuador. Fue escogida esta zona por los antecedentes de producción del denominado Jabón Prieto a partir de las nueces de la Jatropha curcas L.

Con un clima cálido seco en verano, que va desde junio hasta noviembre, en épocas normales; y el cálido Iluvioso en época de invierno, que va de diciembre a mayo (GAD- Gobierno Autonómo Descentralizado Municipal de Chone. Geografía., 2013).

La investigación estuvo conformada en dos partes:

1. Estudio Descriptivo de la elaboración del jabón artesanal. Cuestionarios aplicados a tres productores de Jabón Prieto de la zona: Yadira Bravo, Rafael Quiñonez, Juan Carlos Mendoza; con el objetivo de establecer similitudes y/o diferencias en el proceso artesanal de producción de Jabón Prieto:

Los cuestionarios tenían cinco preguntas:

1. ¿Desde cuándo produce el Jabón Prieto?;

2. ¿Dónde aprendió el proceso?;

3. ¿Con qué frecuencia produce el Jabón Prieto?;

4. ¿Ha realizado algún análisis químico de su producto?;

5. ¿Puede describir el proceso de obtención del Jabón Prieto?

2. Comparación de dos formas de elaboración de Jabón Prieto:

A. Jabón obtenido del aceite de Jatropha en los laboratorios del INIAP en tres producciones que se conservaban de junio de 2012. Para ello se tomó al azar de cada producción piloto una muestra de los jabones. Este jabón se obtuvo mediante la saponificación del aceite de Jatropha, obtenido mediante extrusión, con sosa cáustica ( $\mathrm{NaOH})$.

B. Jabón obtenido de forma artesanal en casa de tres productores. Se tomaron tres jabones al azar de cada productor hechos en el mes de marzo del año 2013.

\section{Diagnóstico de laboratorio:}

Se determinó en el Laboratorio CESAL (Centro de Soluciones Analíticas Integrales) las siguientes propiedades y componentes de los jabones:

Organolépticos: 1.Color, 2.Olor, 3.Consistencia, Físico Químicos:

1. Humedad, \%; 2. Potencial de hidrógeno $(\mathrm{pH})$ según AOAC (1995); 3. Solubilidad según normas 
USP 30 (2007); 4. Materia grasa, según (INEN 823, 1981), \%

\section{Bacteriológicos:}

1. Recuento de aerobios mesófilos, UFC g ${ }^{-1}$; 2.Ausencia o presencia de Echerichia coli, UFC g ${ }^{-1}$; 3.Ausencia o presencia de Salmonella sp y Shigelia sp, UFC g ${ }^{-1}$; todos según criterios de USP 30 (2007).

Procesamiento estadístico:

Los datos fueron tabulados en el procesador de SPSS v 20.1 (SPSS, 2011). Se planteó para cada tipo de datos la prueba de hipótesis para dos medias para un $\mathrm{P}<0.05$.

\section{Resultados y Discusión}

1 - Estudio descriptivo.

Los tres productores son coincidentes en las respuestas, ya que aprendieron a hacer el Jabón Prieto con su familia desde pequeños, llevan más de 20 años en esta actividad y no han investigado la calidad del jabón en ningún laboratorio; plantean que ésta es confiable pues no han tenido ningún rechazo (Cuadro 1).

Cuadro 1. Respuestas compendiadas de cada productor.

\begin{tabular}{|l|c|c|c|}
\hline Preguntas & Productor & Productor & Productor \\
\hline $\begin{array}{c}\text { Tiempo que produce Jabón } \\
\text { Prieto, años }\end{array}$ & 26 & 25 & 3 \\
\hline $\begin{array}{l}\text { 2. ¿Dónde aprendió a hacer el } \\
\text { Jabón? }\end{array}$ & Familia & Familia (padre) & Familia (madre) \\
\hline $\begin{array}{l}\text { 3. Producción anual y cantidad. } \\
500 \text { unidades }\end{array}$ & $\begin{array}{c}\text { Trimestral/ } \\
\text { unidades }\end{array}$ & $\begin{array}{c}\text { Senestral / 500 } \\
\text { unidades }\end{array}$ \\
\hline 4. Análisis de laboratorio & No & No & No \\
\hline
\end{tabular}

Esta actividad la tienen como una fuente de ingresos adicionales y cada uno tiene una frecuencia diferente de producción.

A continuación se describe el proceso de obtención del Jabón Prieto, que fue coincidente en los tres productores; cuyos volúmenes o pesos promedios se especifican, que fueron obtenidos empíricamente en cada producción del producto.

1. Recolección del fruto maduro de piñón.

2. Secado de los frutos al sol, aproximadamente 10 días (37 Kg).

3. Descascarado de los frutos hasta obtener las pepa negra $(23 \mathrm{Kg})$.

4. Pelado de la pepa negra hasta obtener un grano blanco $(21 \mathrm{Kg})$.

5. Remojado 24 horas el grano blanco (50 litros de agua).

6. Pesado de la ceniza de seíbo (Erythrina crista-galli) (46 Kg).

7. Remojado de la ceniza por $24 \mathrm{~h}$ (100 litros de agua).

8. Filtrado de la ceniza disuelta en agua.

9. Obtención de un concentrado llamado lejía de seíbo (100 litros de lejía).

10. Cocción del grano blanco con la lejía hasta obtener un grano blando, durante aproximadamente un día.

11. Adición de la grasa de vaca $(23 \mathrm{Kg}$ ), conocida como sebo, la misma que se va derritiendo con ayuda de la lejía hirviendo, hasta obtener una textura cremosa. 
12. Cocción durante aproximadamente tres días con agitación constante.

13. Vertimiento en un molde hasta que solidifique (36 horas).

14. Corte en rectángulos de un peso aproximado de $80 \mathrm{~g}$.

15. Embalado en hojas de plátano (Musa sp.)

16. Almacenamiento para la venta.

Como se observa la producción de este Jabón se realiza con insumos locales totalmente, de una forma ecológica y que apunta a una sostenibilidad.

2. Comparación de los dos tipos de jabón.

Los resultados que se midieron para evaluar la calidad de este jabón artesanal comparándolo con el obtenido en el INIAP se muestran a continuación.

\section{Organoleptia}

En la tabla 1 se mencionan las principales características de los dos tipos de jabones, que como se observa muestran diferencias en el color y olor. El jabón del INIAP, obtenido de la saponificación del aceite del piñón con hidróxido de sodio, tiene una consistencia sólida, similar a la del jabón artesanal, aunque en las cenizas de la madera (fuente de obtención de la lejía) predomina el hidróxido de potasio sobre el hidróxido de sodio (SCHUMANN; SIEKMANN, 2005). Está descrita la saponificación con hidróxido de potasio, produce un jabón líquido (CAVITCH, 2003).

La composición del aceite de Jatropha, según la literatura revisada, demuestra que en su composición predominan los ácidos grasos insaturados en un 80\% según (BERCHMANS, HIRATA, 2008) y (CHHETRI et al., 2008) y que, en las grasas de vacuno predominan los saturados (BAYLEY, 1984). Por lo que se deduce que, la adición del sebo de vaca permite la consistencia sólida del jabón artesanal.

Cuadro 2.- Evaluación organoléptica de los dos tipos de jabones.

\begin{tabular}{|l|l|l|l|}
\hline Tipo de jabón & Color & Olor & Consistencia \\
\hline Jabón INIAP & verdoso & inoloro & sólido \\
\hline Jabón artesanal & café & vegetal & sólido \\
\hline
\end{tabular}

El color del jabón artesanal es más oscuro debido a que en el proceso el aceite se produce por calentamiento e influye la lejía obtenida de forma artesanal de la filtración de la ceniza que es de color oscuro.

Aunque no existe ningún acuerdo para medir el olfato (SYNNOTT, 1996) y existe una revisión muy detallada de los olores realizada por (BONADEO, 2005), que plantea la discusión entre la ciencia — basada en la razón y en el sentido de la vista — y el olfato, que funciona con una lógica distinta. El olor del jabón artesanal es como el del fruto seco, parecido al piñón.

\section{Físico-Químicos}

Los valores promedios de las variables físico químicas de los jabones se muestran en la siguiente tabla. 
Cuadro 3 - Comparación físico química de los dos tipos de jabón, $\mathrm{X} \pm$ ES.

\begin{tabular}{|l|c|c|c|c|c|c|}
\hline Tipo de jabón & $\mathrm{pH}$ & $\begin{array}{c}\mathrm{CV}, \\
\%\end{array}$ & $\begin{array}{c}\text { Humedad, } \\
\%\end{array}$ & $\begin{array}{c}\mathrm{CV}, \\
\%\end{array}$ & $\begin{array}{c}\text { Materia grasa, } \\
\%\end{array}$ & $\begin{array}{c}\mathrm{CV}, \\
\%\end{array}$ \\
\hline Jabón INIAP & $9.56 \pm 0.31$ & 3.24 & $5.63 \pm 0.36$ & 6.39 & $55.50 \pm 0.64$ & 1.15 \\
\hline Jabón artesanal & $9.91 \pm 0.70$ & 7.06 & $12.73 \pm 0.89$ & 6.99 & $34.77 \pm 1.53$ & 4.40 \\
\hline $\mathrm{P}$ & 0.129 & - & 0.002 & - & 0.001 & - \\
\hline
\end{tabular}

Valores en las comunas con $\mathrm{P} \leq 0.05$ difieren (Prueba $\mathrm{T}$ ).

Los valores de $\mathrm{pH}$ son similares en ambos jabones, que demuestran su alcalinidad $(P=0.129)$.

Se encontraron diferencias significativas entre ambos tipo de jabones para el contenido de humedad y materia grasa. Aunque el jabón artesanal es sólido, posee mayor contenido de humedad (12.73\%), ya que en el proceso de saponificación se utiliza la lejía de las cenizas de madera que mayormente está compuesta por hidróxido de potasio y el proceso de secado es al aire libre.

A su vez, este tipo de jabón posee menor contenido de materia grasa, debido a que en el proceso artesanal por cocción no se alcanza a extraer toda la grasa de las semillas y hay menor saponificación. Por lo que la evaporación del agua no es la solución para aumentar el contenido de materia grasa, sino que se debe determinar de una manera adecuada, el grado de saponificación de las materias primas utilizadas.

No obstante la solubilidad encontrada fue igual para ambos tipos de jabón y se declaran como ligeramente solubles.

Los procesos artesanales pueden tener variaciones, que para el caso de estos tres productores es mínimo según los coeficientes de variación encontrados para las variables diagnosticadas en laboratorio (cuadro 2). Como era de esperar los resultados obtenidos con el aceite industrial presentaron menor variabilidad.

\section{Bacteriología}

La Revolución Industrial supuso una profunda transformación en la economía y la sociedad. Los cambios originados más inmediatos se produjeron en los procesos de producción: ¿qué, cómo y dónde se producía? Esto condujo a que se tuvieran que extremar las precauciones, para evitar microorganismos perjudiciales en los alimentos y su conservación, como también en el agua (FORYSTHE, 2000)

Aunque el jabón es un producto de limpieza, es importante conocer su calidad bacteriológica, debido a que en su uso participa cualquier parte del cuerpo humano.

Cuadro 4 - Conteos bacteriológicos de los dos tipos de jabones.

\begin{tabular}{|l|l|l|l|l|l|l|}
\hline & \multicolumn{3}{|c|}{ Producción artesanal } & \multicolumn{3}{c|}{ Producción industrial } \\
\hline Parámetro & $\begin{array}{l}\text { Yadira } \\
\text { Bravo }\end{array}$ & $\begin{array}{l}\text { Rafael } \\
\text { Quiñonez }\end{array}$ & $\begin{array}{l}\text { Juan } \\
\text { Mendoza }\end{array}$ & INIAP & INIAP & INIAP \\
\hline $\begin{array}{l}\text { Recuento de aerobios } \\
\text { mesófilos, UFC g-1 }\end{array}$ & $<10$ & $<10$ & $<10$ & $<10$ & $<10$ & $<10$ \\
\hline $\begin{array}{l}\text { Ausencia o presencia de } \\
\text { Echerichia coli, UFC g }\end{array}$ & Ausencia & Ausencia & Ausencia & Ausencia & Ausencia & Ausencia \\
\hline $\begin{array}{l}\text { Ausencia o presencia de } \\
\text { Salmonella sp y } \\
\text { Shigelia sp, UFC g- }\end{array}$ & Ausencia & Ausencia & Ausencia & Ausencia & Ausencia & Ausencia \\
\hline
\end{tabular}


Las bacterias mesófilas aerobias, se definen como un grupo heterogéneo de bacterias capaces de crecer entre 15 y $45^{\circ} \mathrm{C}$, con un rango óptimo de $35^{\circ} \mathrm{C}$. La presencia de este tipo de microorganismos refleja la calidad sanitaria de los productos analizados, indicando además de las condiciones higiénicas de la materia prima, la forma como fueron manipulados. Mediante el recuento de microorganismos aerobios mesófilos se estima la microbiota, pero sin identificar tipos de microorganismos (JAWETZ et al., 2005).

Los valores obtenidos fueron iguales para ambos tipos de jabones. Es importante señalar que los valores de mesófilos aerobios estuvieron por debajo de 10 UFC, que es permisible para este tipo de producto.

No hay presencia de contaminación por Echerichia coli, que señala indirectamente a un proceso realizado aún en condiciones artesanales en el campo, de forma higiénica. No se encontró presencia de Staphylococcus sp., que es importante, teniendo en cuenta que estos microorganismos se encuentran fundamentalmente en la piel y mucosas de los humanos y son bacterias consideradas patógenas. Tampoco se encontró presencia de Shigelia sp.

\section{Conclusiones}

Los procesos artesanales de producción de jabón prieto se han mantenido por generaciones y son similares en las actividades que se realizan. Desde el punto de vista organoléptico el jabón artesanal con respecto al jabón obtenido del aceite de Jatropha es más oscuro y con un olor más penetrante parecido al de fruto seco, que posee un menor contenido de materia grasa, mayor humedad, pero con igual solubilidad. Desde el punto de vista bacteriológico ambos jabones son aptos para el consumo.

\section{Agradecimientos}

Es necesario agradecer a los productores de Jabón Prieto del Cantón de Chone que permitieron participar en sus procesos de fabricación de este producto.

\section{Tecnology for crafted production of dark soap of Jatropha curcas L.}

\section{Abstract}

Soap crafted production is a local practice in many places around the world, which in Ecuador is done in Canton de Chone in the province of Manabí, but such process is not described in scientific literature, yet and its techniques are passed from parents to children. In this research has been tried to describe the technology used in the crafted production of dark soap with Jatropha's nuts, employing an observational design supported by surveys to three manufacturers. Three soap productions obtained from Jatropha oil with sodium hydroxide made in INIAP laboratories were also compared with samples from the three manufacturers' crafted production. The organoleptic, physical-chemical and bacteriological characteristics were diagnosed in an accredited laboratory. The crafted soap production processes are similar and it was described the technology in which external supplies expenses were not found, which points to a sustainable production. Crafted soap is darker and has a penetrating aroma much like the dry fruit, both are solid; which is expressed in the crafted soap by the addition of cow fat with fat saturates acids. The obtained soaps exposed similar alkaline $\mathrm{pH}$ values. The crafted soap showed greater humidity $(12.73 \%)$ and lesser fat content (34.77\%). The variability of the physical-chemical indexes was higher for the crafted soap but always with a coefficient of variation lesser than $10 \%$, which shows the similarity in the manufacturers processes. From the 
bacteriological point of view both soaps are declared suitable for use with a total counting of total mesophylls lesser than 10 CFU (colony forming units), and absence of Echerichia coli, Salmonella sp. y Shigelia sp.

Keywords: Bacteriological. Crafted production. Quality. Soap. Sustainability.

\section{Literatura Citada}

ASSOCIATION OF OFFICIAL AGRICULTURAL CHEMISTS (AOAC). Official Methods of Analysis of the Association of Official Agricultural Chemists, 16th ed. AOAC. Washington, DC, USA1995.

BAYLEY, A. Grasa Animal. In: Aceites y grasa industriales. S.I.: Reverté, 1984. p. 115-121.

BERCHMANS, J.; HIRATA, S. Biodiesel production from crude Jatropha curcas L. seed oil with a high content of free fatty acids. Bioresource Technology, Issue 99, p. 1716-1721. 2008.

BIODIESELSPAIN. Rendimento de Cultivos Oleaginogos por Hectares Aptos para Biodísel. 2006. Disponível em: http://www.biodieselspain.com/2006/10/14/rendimiento-de-cultivos-oleaginosos-por-hectarea-aptos-parabiodiesel / Acesso em: 15 fev. 2013.

BONADEO, M,. Odotipo: historia natural del olfato y su función en la identidad de marca. Buenos Aires: Universidad Austral. 2005.

BRUINSMA, B. Producción de Biodiesel de Palma aceitera y Jatropha en la Amazona del Perú y el Impacto para la Sostenibilidad. Un análisis Sostenible del Ciclo de Vida., S.I.: AGRITERRA. 2009.

CAVITCH, S. Guía Práctica para Hacer Jabón: una extensa guía con recetas, técnicas y métodos. Barcelona: Paidotribo, 2003.

CHHETRI, A. et al. Non-Edible Plant Oils as New Sources for Biodiesel Production. International Journal of Molecular Science, v. 9, p. 169-180, 2008.

CORDERO, J., BOSHIER, D.; BARRANCE, A.. Árboles de Centroamérica: un manual para extensionistas. S.I.: IICA/CAT, 2003

ESTEVES, A. Anteproyecto de una Instalacao de Extraccao de Óleo de Purgueira en Cabo Verde. S.I.: Missao de Estudios agronomicos do Ultramar, 1960.

FORYSTHE, S. Higiene de los alimentos. Microbiología y HACCP. 2. ed. S.I.: Acribia, 2000.

GOBIERNO AUTONÓMO DESCENTRALIZADO MUNICIPAL DE CHONE (GAD). Geografía, 2013. GAD Chone. Disponível em: < http://www.chone.gob.ec/index.php?op=2\&pub=2>Acesso: 18 dez. 2012.

GMÜNDER, S.; SINGH, R.; PFISTER, S.; ADHELOYA A.; ZAH, R. Environmental Impacts of Jatropha curcas Biodiesel in India. Journal of Biomedicine and Biotechnology. Volume 2012, 10 p. doi:10.1155/2012/623070

GUBITS, G.; MITTELBACH, M.; TRABI, M. Exploitation of the Tropical oil Seed Plant Jatropha Curcas L. Bioresource Technol, S.I., v. 67, n. 1, p. 37-42, 1999.

INEN 823. Agente Tensoactivos. Determinación de Materia Grasa Total. S.I.: s.n., 1981. Norma Técnica. 
IPCC. Cambio Climático 2001. Informe de Síntesis. Resumen para Responsables de Políticas. S.I.: IPCC, 2001. p. 38.

JAWETZ, E., MELNICK, J.; ADELBERG, A. Microorganismos Entéricos Gram Negativos. S.I.: Mac Graw Hill, 2005.

KARAVINA, C.; ZIVENGE, E.; MANDUMBU, R.; PARWADA, C. Jatropha Curcas. Production in Zimbawe: uses, challenges and the way forward. Modern Applied Sciences, v. 5, n. 2, 239-243, 2011.

SCHUMANN, K.; SIEKMANN, K. Soaps. En: Ullmann's Encyclopedia of Industrial Chemistry. doi 10.1002/14356007.a24_247 ed.s.I.: Wiley-VCH, Weinheim., p. 247. 2005

SYNNOTT, A. A Sociology of Smell. Canadian Review of Sociology and Anthropology, v. 33, n. 4, pp. 437-460, 1996.

UNITED STATUS PHARMACOPEIAL CONVENTION (USP) Inc. 2007. USP 30. Thirty Revision. The National Formulary twenty two. Edition NF 22 USA.

\section{Histórico}

Submetido em 18/07/2013

Aceito em: 17/09/2014 